\title{
Correction to: Integrating IVFRN-BWM and Goal Programming to Allocate the Order Quantity Considering Discount for Green Supplier
}

\author{
Peide Liu $^{1} \cdot$ Ayad Hendalianpour $^{2}$ (D) Mahnaz Fakhrabadi ${ }^{3} \cdot$ Mohamdreza Feylizadeh $^{4}$
}

Published online: 8 January 2022

(c) The Author(s) under exclusive licence to Taiwan Fuzzy Systems Association 2022

\section{Correction to: Int. J. Fuzzy Syst.}

https://doi.org/10.1007/s40815-021-01181-z

The Original version of this article unfortunately contained some mistakes in the Scientific biography section and the author wants to modify it.

The Correct Biography is given below:

Mahnaz Fakhrabadi accomplished her BSc in Applied Mathematics and MSc in Industrial Engineering at the Department of Industrial Engineering, Amirkabir
University of Technology (Tehran Polytechnic), Tehran, Iran. Now, she is a PhD Research Scholar at the Department of Business and Management Sciences at University of NHH Norwegian School of Economics, Bergen, Norway. She has worked on risk management, operations research, green and sustainable supply chain, logistics and distribution networks. She is currently studying on stochastic optimization. She is also a reviewer of Cleaner Production Journal.

The original article can be found online at https://doi.org/10.1007/ s40815-021-01181-z.

$\triangle$ Ayad Hendalianpour

Hendalianpour@ut.ac.ir

1 School of Management Science and Engineering, Shandong University of Finance and Economics,

Jinan 250014, Shandong, China

2 School of Industrial Engineering, College of Engineering, University of Tehran, Tehran 1439955961, Iran

3 Department of Business and Management Science, NHH Norwegian School of Economics, 5045 Bergen, Norway

4 Department of Industrial Engineering, Shiraz Branch, Islamic Azad University, Shiraz, Iran 